\title{
ParalORde!?
}

\section{GEOGRAFIA FÍSICA E ENSINO DE GEOGRAFIA}

A proposta de organização de um número especial de Para Onde sobre Geografia Física e Ensino de Geografia visa dar notoriedade as temática investigadas no III Colóquio de Pesquisadores em Geografia Física e Ensino de Geografia realizado entre os dias 21 a 24 de novembro de 2018 na cidade de Pelotas-RS.

O Colóquio de Pesquisadores em Geografia Física e Ensino de Geografia foi idealizado no ano de 2014, no Instituto de Geociência da Universidade Federal de Minas Gerais, em Belo Horizonte, sendo organizado pelo Grupo de Estudos e Pesquisas em Ensino de Geografia (GEPEGEO) em parceria com o Núcleo de Estudos e Pesquisas em Geografia, Ensino e Ambiente (NúcleoGEA) do Instituto de Estudos Socioambientais da Universidade Federal de Goiás.

A segunda edição do Colóquio foi realizada no ano de 2016 na Universidade Federal de Goiás, Goiânia, sob a responsabilidade do NúcleoGEA que contou também com a parceria do GEPEGEO. Nessas duas edições do Colóquio foi possível identificar a abrangência das pesquisas desenvolvidas em instituições do território nacional e reunir diferentes sujeitos que se dedicam a pesquisar e refletir sobre a Geografia Física a partir das discussões e práticas realizadas na Área de Ensino de Geografia.

A terceira edição do Colóquio foi organizada pelo LEGA (Laboratório de Educação Geográfica Ambiental), LEAGEF (Laboratório de Estudos Aplicados em Geografia Física) da Universidade Federal de Pelotas/UFPel e NEEGEO (Nucleo de Estudos em Educação e Geografia) da Universidade Federal do Rio Grande do Sul/UFRGS, além da parceria dos Programas de Pós-Graduação PPGeo/UFPel e POSGEA/UFRGS.

Destinado aos docentes e estudantes do curso de graduação e pós-graduação em Geografia e áreas afins, professores da Educação Básica, pesquisadores da linha de ensino de Geografia, Geografia Física e demais interessados no tema, a temática elegida para o III Colóquio de Pesquisadores em Geografia Física e Ensino de Geografia, versou sobre "As contribuições da Geografia Física para o ensino de Geografia: Práticas, Perspectivas e Aprendizagens", com o objetivo de fomentar as discussões sobre a interface entre Geografia Física e Ensino de Geografia e as perspectivas de formação e atuação docente no cenário atual, político e educacional, bem como estreitar e consolidar a discussão teórica e metodológica da Geografia Física e do Ensino em âmbito nacional.

Os textos aqui apresentados são de autoria de diferentes pesquisadores, participantes do III Colóquio de Pesquisadores em Geografia Física e Ensino de Geografia, e contemplam temas que envolvem a discussão e práticasàde temáticas relacionadas à Geografia Física e o Ensino, tendo o trabalho de campo como possibilidade de formação e atuação docente, as Diretrizes Curriculares e as temáticas físicas ambientais no ensino de Geografia e propostas teóricas e metodológicas para o ensino de Geografia Física e temáticas físico-naturais. 
Os autores, sempre preocupados com a relação da Geografia Física e o Ensino de Geografia, nos trazem contribuições efetivas e relevantes que contribuem para um repertório de práxis para a análise do espaço geográfico.Cabe aos leitores refletirem sobre os textos aqui expostos e construirem as suas avaliações. È preciso transpor a teoria e reavaliar as nossas práticas com as contribuições trazidas pelas textualizações. O convite está posto!

Porto Alegre, 10 de novembro de 2019.

Prof ${ }^{\mathrm{a}}$. Dr ${ }^{\mathrm{a}}$. Liz Cristiane Dias - UFPEL

Prof. Dr. Antonio Carlos Castrogiovanni - UFRGS 